\title{
Addressing supply side factors to improve family planning and reproductive health services in the Indian National Health Insurance Scheme in Uttar Pradesh
}

Arupendra Mozumdar

Population Council

Kumudha Aruldas

Population Council

Aparna Jain

Population Council

Laura Reichenbach

Population Council

Robin Keeley

See next page for additional authors

Follow this and additional works at: https://knowledgecommons.popcouncil.org/departments_sbsr-rh

Part of the Demography, Population, and Ecology Commons, Family, Life Course, and Society

Commons, Inequality and Stratification Commons, and the International Public Health Commons

How does access to this work benefit you? Let us know!

\section{Recommended Citation}

Mozumdar, Arupendra, Kumudha Aruldas, Aparna Jain, Laura Reichenbach, Robin Keeley, and M.E. Khan. 2016. "Addressing supply side factors to improve family planning and reproductive health services in the Indian National Health Insurance Scheme in Uttar Pradesh," Policy brief. Washington, DC and New Delhi: Population Council, The Evidence Project. 


\section{Authors}

Arupendra Mozumdar, Kumudha Aruldas, Aparna Jain, Laura Reichenbach, Robin Keeley, and M.E. Khan 


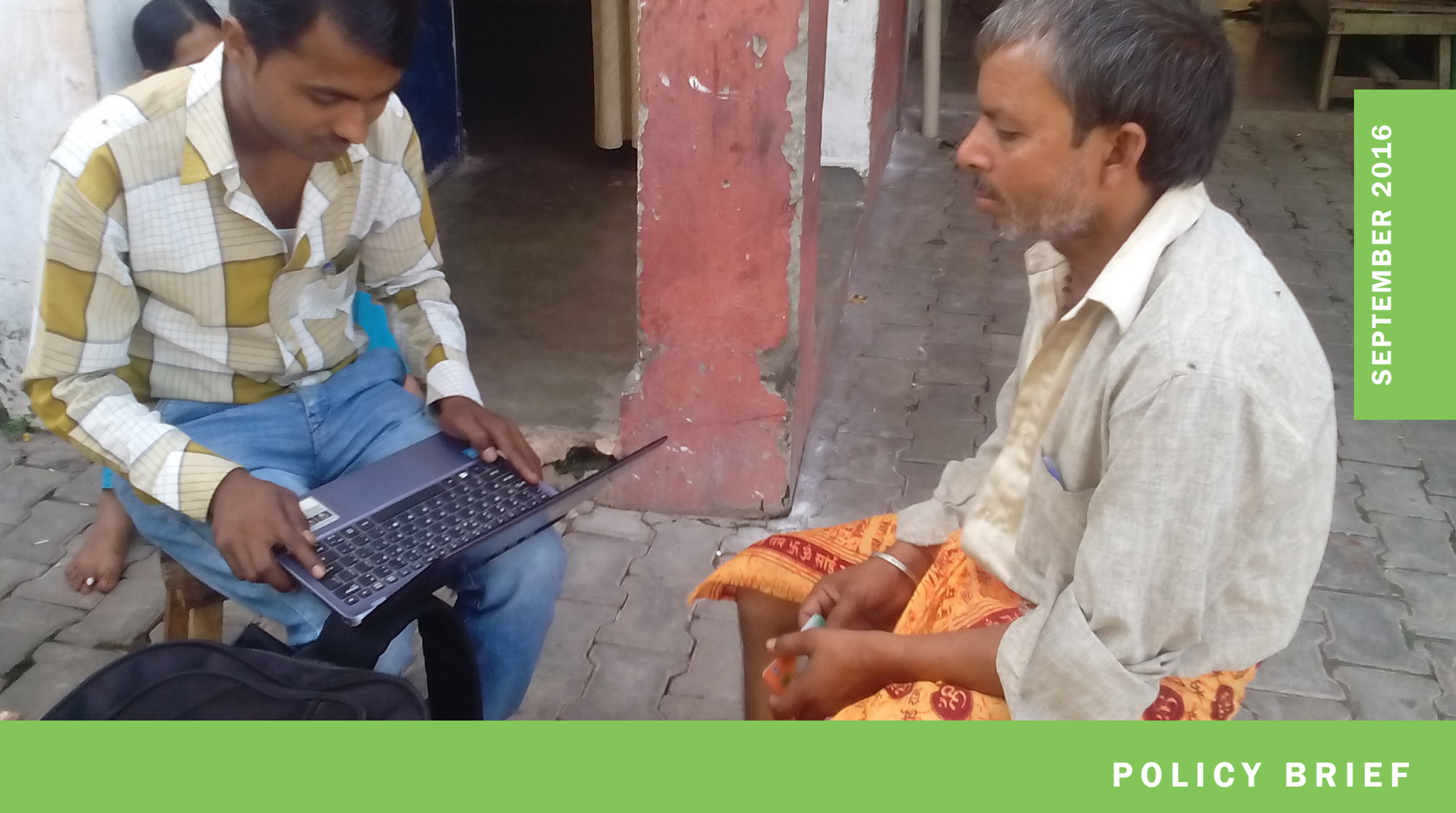

\section{Addressing supply side factors to improve family planning and reproductive health services in the Indian National Health Insurance Scheme in Uttar Pradesh}

\section{KEY FINDINGS}

Below poverty line family lists are not often updated so eligible families are likely missed.

Many RSBY-enrolled families think that empaneled private hospitals would be good for FP/RH services, but actual usage is very low.

Systemic issues such as mismatched enrollee data or poor connectivity with the $R S B Y$ system at the point of service can cause denial of coverage.

Long reimbursement times or denials of coverage can decrease the desire or ability for private hospitals to remain empaneled hospitals.
The Indian National Health Insurance Scheme, Rashtriya Swasthya Bima Yojana (RSBY), was launched by the Ministry of Labour and Employment, Government of India in 2008 to promote equitable access to health services through the private and public sectors. This scheme is intended to offer economically disadvantaged families living below the poverty line (BPL) in urban and rural areas access to a pre-specified package of health services including general surgery, general medical care, pediatric care, gynecological care, family planning $(\mathrm{FP})$ and other reproductive health $(\mathrm{RH})$ services, dental, ophthalmology, urology, neurosurgery, and oncology. Though the RSBY program includes a range of services provided through both the public and private sectors, this study focuses only on FP/RH services provided through participating (empaneled) private hospitals. In India, FP/RH services are available free of charge in the public sector, however offering RSBY coverage in the empaneled private hospitals could help increase access to those services for BPL families.

Almost eight years into the program, this is an opportune time to examine usage levels and barriers and facilitators to the program's effectiveness. The Evidence Project conducted a study among the urban poor in Uttar Pradesh to look at awareness and use of the RSBY program and FP/RH services, concerns of those administering the program and providing services, and provide programmatic recommendations for improvement.

\section{USAID Evidence}




\section{STUDY DESIGN}

A cross-sectional study was conducted among BPL families in 51 urban slums using both quantitative and qualitative methods in three cities of Uttar Pradesh, India: Allahabad, Kanpur, and Lucknow (which had 1,000; 9,000; and 16,000 RSBY-enrolled families, respectively). The sample size of 800 was distributed according to the proportion of RSBY-enrolled families in the three cities, with city samples of 100 in Allahabad, 300 in Kanpur, and 400 in Lucknow. Among the listed RSBY households with eligible women (married and between the ages of 18-35 years), participants from 810 households were interviewed. In many households, women and men were not both available for the interview, therefore, from 810 households, 726 women and 640 men were interviewed.

Interviews were also conducted with hospital heads and doctors of the RSBY empaneled hospitals, and ration shop owners from the three cities.

\section{USE OF RSBY ENTITLEMENTS FOR FP AND RH}

Among study participants, no women and $0.2 \%$ of men reported use of FP services in their families since receiving their last RSBY card. For delivery services, only $2 \%$ of RSBY-enrolled women who delivered within the two years prior to the survey reported using RSBY. Interestingly, $22 \%$ of these RSBY-enrolled women delivered in a nonempaneled private clinic or hospital. Yet nearly half of women $(46 \%)$ and more than half of men (56\%) interviewed said that empaneled private hospitals would be better for FP/RH services. This shows a gap between knowledge and action in using RSBY for FP/RH services. To better understand RSBY supply and demand side factors that could be contributing to this low awareness and use of RSBY for FP/RH, a graphic depiction of the six pathways of action among the four key stakeholders in the RSBY program (Figure 1) was developed.

This brief focuses on factors in pathways 1, 2, 4, 5, and 6 - which describe the relationships among the State Agency for Comprehensive Health Insurance (SACHI), which administers the RSBY program at the state level, the insurance company that implements RSBY, the empaneled hospitals that provide RSBY services, and RSBY clients - that impact supply of RSBY services, specifically FP/ RH services. A companion brief examines demand side factors associated with pathways 3 and 4, which illustrate the relationships between the beneficiaries, insurance company, and empaneled hospitals.

\section{FIGURE 1. PATHWAYS OF ACTION AMONG THE STAKEHOLDERS IN THE RSBY PROGRAM}

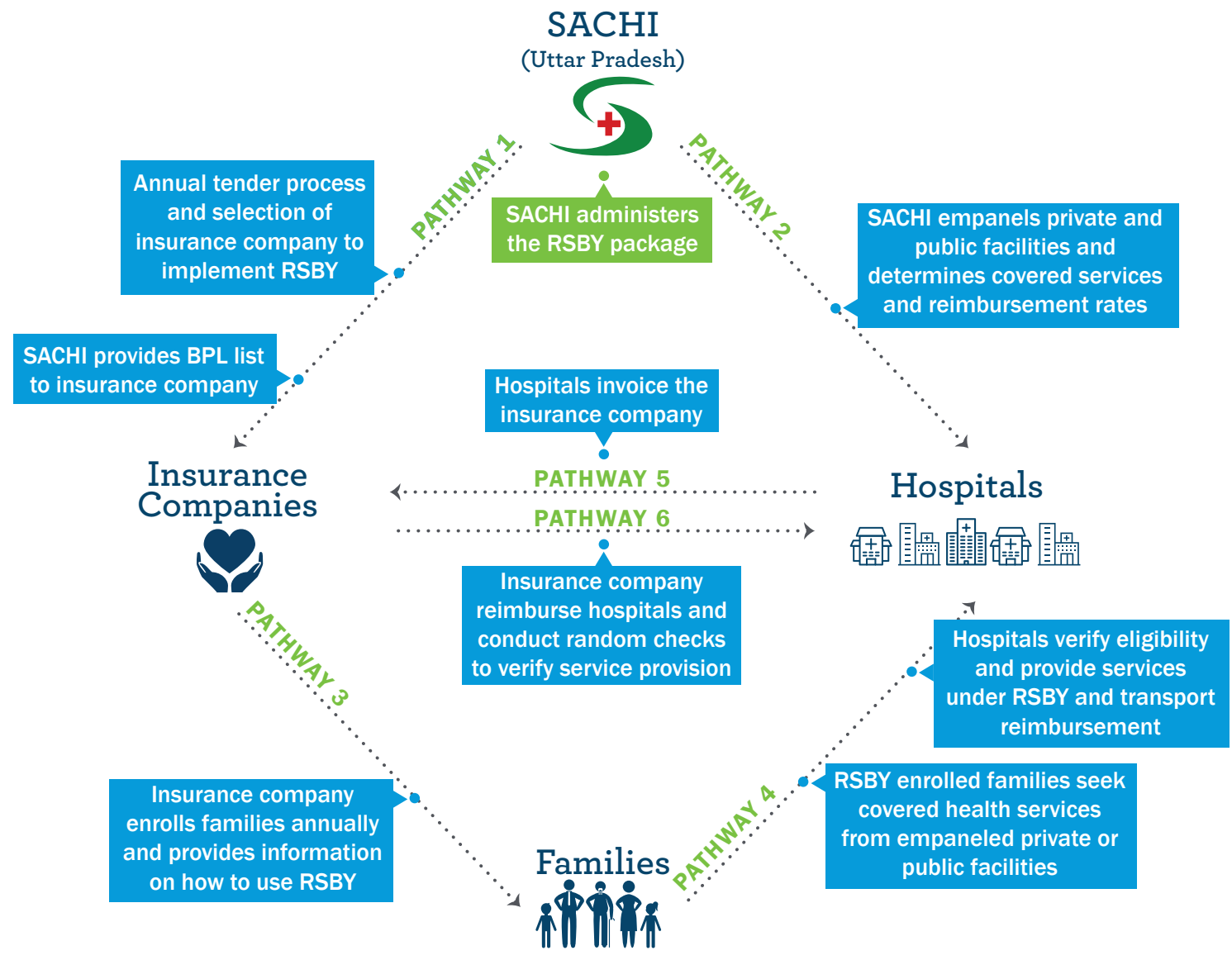


This study identified several supply side factors of the insurance scheme that hinder knowledge of and access to services, including FP/RH services, among enrollees and potential enrollees, some of which are highlighted here:

\section{Pathways 1 and 2: SACHI, the Insurance Company, and Empaneled Hospitals}

SACHI manages the overall RSBY scheme, including selecting (through a competitive process) the insurance companies that implement the RSBY program and empaneling private hospitals to provide services to RSBY clients, as shown in Pathways 1 and 2 in Figure 1. SACHI also sets the services covered and pays the premiums for these services to the insurance companies. Several key challenges were identified within these pathways, however, to the supply side of the RSBY program.

Pathway 1 Challenge: Insurance companies identify potential RSBY enrollees through the BPL family list provided by SACHI. However, this list was last updated by the statae government in Uttar Pradesh in 2002. Therefore, insurance companies are likely not reaching the most current BPL families. In addition, addresses were poorly recorded on the BPL family list, hindering efforts to enroll BPL families.

\section{RECOMMENDATION}

The list of the BPL families in Uttar Pradesh should be updated at least once every five years. This will allow insurance companies to contact current BPL families to encourage enrollment in RSBY and will help to reduce mismatched data at the time of service delivery, reducing potential refusal of the RSBY card by empaneled hospitals.

Pathway 1 Challenge: To win the bid to become the RSBY insurance company, companies often quote a low premium to the government, which becomes impractical to implement and makes it difficult to reimburse empaneled hospitals for too many RSBY clients.

\section{RECOMMENDATION}

The Government should consider revising the bidding process and premiums, and assess families' willingness to pay more than the current registration fee. Furthermore, the Government should consider engaging insurance companies in a particular district for longer periods of time, instead of annual bids. This could help insurance companies feel more confident investing in systems to improve the service, reduce the need for families to reenroll annually, and generally reduce confusion.
Pathway 2 Challenge: Empaneled hospitals reported that the reimbursement amounts set by SACHI for many health services in general are very low. Often the RSBY package rates are well below market rates, so providing many of the services under RSBY is a financial loss to the hospital.

\section{6}

"For example, if the package for a general patient is Rs. 500, then besides medicine and diagnostic tests, we have to provide food and Rs. 100 for transportation. So admitting such a patient causes a lot of trouble. I don't think any 40 or 50 bedded hospital in our city can afford to provide service with such a low package. Many hospitals have also appealed to revise the package."

-Hospital head, Lucknow

\section{RECOMMENDATION}

SACHI could revise the reimbursement rates for services under the RSBY package in consultation with representatives of empaneled private hospitals. A reasonable reimbursement rate of health services will encourage the empaneled private hospitals to provide the health services under the RSBY, and potentially encourage more private hospitals to become empaneled hospitals which would increase access for BPL families.

Pathway 2 Challenge: The RSBY program only covers two types of FP methods, IUD and sterilization. Private hospitals do not carry condoms or oral contraceptive pills because these are typically sold by chemist shops. However, the government recently added injectable contraceptives to the public health system services, so this method should also be available in the RSBY package.

\section{RECOMMENDATION}

To enhance choice for women who seek FP services from empaneled private facilities, SACHI should include injectable contraceptives in the RSBY insurance package.

\section{Pathway 4: Empaneled Hospitals and RSBY Families}

Challenge: During the house-listing activity of the study, 1,239 non-RSBY BPL families were asked about their reasons for not enrolling. Nearly 94\% reported that they did not know such a scheme existed. Among those enrolled in 
RSBY, there are low levels of knowledge about RSBY services and benefits. Further, among those who visited empaneled private hospitals for health services, 10\% did not know the processes at the facility for using the RSBY insurance, 13\% failed to produce their RSBY card and complete the appropriate paperwork at the time of admission, and about $65 \%$ of women and $55 \%$ of men reported that the hospital declined the card, leading to out of pocket payments for covered services or to denial of services.

\section{RECOMMENDATION}

Empaneled hospitals can ensure that they have at least one person on staff at all times who is well versed in the rules and regulations of RSBY so that they can assist these clients.

Challenge: Often the information retrieved by swiping the RSBY card does not match the client's information, due to poor internet connections to the insurance company's system or incorrect or incomplete data in the system, which prevents clients from being able to use the card for covered services.

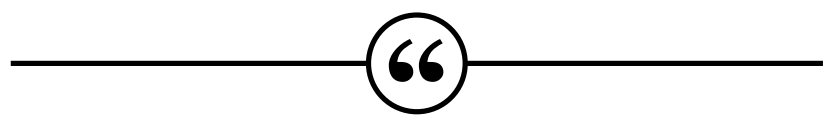

"The other point is that patients too need some awareness on how to use the card. They think that they will just get Rs. 30,000 from us. It's not like that. We also need to have some special rule for an emergency patient. If someone comes in a bedridden condition, or in a coma, how we can register his/her fingerprint. Sometimes there are network-problems, telephone does not work. We are clueless in those situations. There should be some rule or policy on what should be done in those situations."

-Doctor, Allahabad

\section{RECOMMENDATION}

The computer enrollment system should be improved to minimize errors in data and biometric information entry that can result in denials of coverage at the point of service. The possibility of linking the RSBY card to the national unique identification number and card (Aadhaar card) issued by the Unique Identification Authority of India should be explored by the government.

\section{Pathway 5 and 6 - Insurance Company and Empaneled Hospitals}

Challenge: It can take months for empaneled hospitals to receive reimbursements from the insurance company, and the insurance company often declines reimbursements after a hospital has provided services, for reasons such as a client's pre-existing conditions, providing the wrong or unnecessary services, or providing services to a nonenrolled person. Such issues discourage hospitals from participating in RSBY, since associated financial losses or delays make it hard for private facilities to meet operating expenses and remain open.

\section{6}

"Our hospital provides all health services to the cardholders. We should get our reimbursements within 20 days from the insurance company. But it gets delayed too much. We did not receive payments for the last eight months."

-Hospital head and doctor, Lucknow

\section{RECOMMENDATION}

The process for reimbursement to the hospitals should be studied by the insurance companies to identify barriers and delays and a mechanism to increase the speed of reimbursements should be developed.

The RSBY scheme has the potential to expand health care access, including FP/RH services, for BPL families. By identifying barriers and potential improvements, this brief is intended to contribute to the increased effectiveness and use of this program.

\section{THE EVIDENCE PROJECT} Population Council Zone 5A, Ground Floor India Habitat Centre, Lodhi Road New Delhi, Delhi 110003

evidenceproject@popcouncil.org

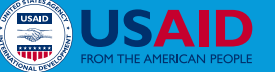
The Evidence Project is made possible by the generous support of the American people through the United States Agency for International Development (USAID) under the terms of cooperative agreement no. AID-OAA-A-13-00087. The contents of this document are the sole responsibility of agreement no. AID-OAA-A-13-00087. The contents of this document are the sole responsibility of
Population Council and do not necessarily reflect the views of USAID or the United States Government. The Evidence Project uses implementation science-the strategic generation, translation, and use Evidence of evidence-to strengthen and scale up family planning and reproductive health programs to reduce unintended pregnancies worldwide. The Evidence Project is led by the Population Council in partnership with INDEPTH Network, International Planned Parenthood Federation, PATH, Population Reference Bureau, and a University Research Network.

Suggested Citation: Mozumdar, A., K. Aruldas, A. Jain, L. Reichenbach, R. Keeley, and M.E. Khan. 2016. “Understanding demand for family planning and reproductive health services through the Indian National Health Insurance Scheme in Uttar Pradesh," Policy Brief. Washington, D.C. and New Delhi: Population Council, The Evidence Project. 